\title{
OS DIFERENTES TIPOS DE COAGULANTES NATURAIS PARA O TRATAMENTO DE ÁGUA: UMA REVISÃO
}

\author{
The use and types of natural coagulants in water treatment
}

https://doi.org/10.18593/eba.24807

Recebido em 8 de julho de 2020 | Aceito em 3 de agosto de 2020

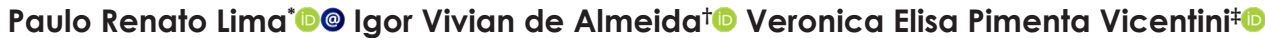

\footnotetext{
Mestre em Biotecnologia Ambiental pela Universidade Estadual de Maringá; Graduado em Engenharia Ambiental pela Universidade Estadual de Maringá; Professor no Instituto Phorte Educacional.

† Mestre e Doutor em Biologia Comparada pela Universidade Estadual de Maringá; Professor no Magistério Superior da Universidade Federal Rural da Amazônia, Campus Capitão Poço.

¥ Mestra e Doutora em Genética pela Faculdade de Medicina de Ribeirão Preto da Universidade de São Paulo; Professora titular no Departamento de Biotecnologia, Genética e Biologia Celular da Universidade Estadual de Maringá.
}

Resumo: Os coagulantes naturais são compostos naturais, como sementes, mucilagem e outros compostos baseados ou não baseados em plantas, que possuem a capacidade de remoção de contaminantes da água, esgotos e efluentes. Seu uso possui forte apelo ambiental, econômico e social, especialmente por se tratarem de compostos facilmente encontrados na natureza, como a moringa, quiabo e cáctus, e, por isso, baratos, aumentando a qualidade de vida da sociedade e mitigando o dano ou impacto ambiental. Esta revisão teve por objetivo apresentar os diferentes tipos de coagulantes naturais, seus respectivos usos e características. Esta pesquisa foi elaborada por meio de consultas na literatura especializada, com cerca de 160 artigos pesquisados e 38 efetivamente utilizados; concentrou-se em discutir os benefícios dos coagulantes naturais frente aos coagulantes químicos, bem como as implicações dos diferentes tipos de coagulantes naturais no tratamento de água, efluentes líquidos e esgotos. Em suma, verificou-se que as questões que envolvem a pesquisa dos coagulantes naturais é um caminho ambientalmente correto, barato e um objetivo a ser alcançado, visto a grande demanda de tratamento de água e efluentes que ocorre ao redor do mundo.

Palavras-chave: Coagulante natural. Contaminação. Água. Tratamento.

Abstract: $\quad$ Natural coagulants are natural compounds, such as seeds, mucilage and other compounds based or not based on plants, which have the ability to remove contaminants from water, sewage and effluents. Its use has a strong environmental, economic and social appeal, especially because these are compounds easily found in nature, such as moringa, okra and cactus, and therefore cheap, increasing the quality of life of society and mitigating damage/ environmental impact. The aim of this review was to present the different types of natural coagulants, their respective uses and characteristics. This research was elaborated through search in the specialized literature, with about 160 researched articles and 38 effectively used, a research that focuses on discussing the benefits of natural coagulants against chemical coagulants, as well as the implications of different types of natural coagulants in the treatment of water, wastewater and sewage. It was found that the issues involving research on natural coagulants are an environmentally friendly, inexpensive way and an objective to be achieved, given the great demand for water and effluent treatment that occur around the world.

Keywords: Natural coagulant. Contamination. Water. Treatment. 


\section{INTRODUÇÃO}

Visa-se transmitir a importância dos coagulantes naturais para o tratamento de água e efluentes líquidos, umavezqueissoatingefortemente os três pilares do desenvolvimento sustentável: meio ambiente, sociedade e economia. No aspecto ambiental, tal ponto relaciona-se com a questão da despoluição, mitigação de danos e impactos ambientais negativos; no quesito social, trata-se de uma melhor qualidade de vida para a população que não dispõe de saneamento básico de qualidade, sendo que o uso de coagulantes naturais, justamente por ser custeável em termos financeiros - e aqui se adentra no terceiro ponto do tripé, o econômico - possui maior grau de viabilidade econômicofinanceira no que se refere ao investimento público em áreas que necessitam de tratamento de água, esgotos e efluentes com maior qualidade. ${ }^{1,2}$

Com a utilização de coagulantes químicos, os métodos tradicionais de clarificação da água que utilizam coagulantes naturais já não são praticados, exceto em países rurais e em desenvolvimento que têm acesso limitado a esses produtos químicos. Isso marcou o início de uma mudança de paradigma para a dependência de coagulantes químicos no tratamento da água turva. ${ }^{1}$

Ao longo dos anos, esse cenário levou gradualmente à estagnação no desenvolvimento de coagulantes naturais. Já existe uma grande lacuna que traz vertentes óbvias entre essas duas variantes coagulantes, na medida em que o método tradicional de clarificação da água se tornou obsoleto. ${ }^{1}$

Portanto, não é recente a utilização dos compostos químicos inorgânicos baseados em alumínio e ferro (III) no tratamento de água, ${ }^{2}$ cujo fim seja um maior uso de coagulantes naturais. Há sempre algum tipo de impacto ambiental negativo no uso de coagulantes químicos, e, portanto, menos sustentáveis. Por exemplo, a concentração de íons de alumínio superior a 50 $\mathrm{g} / \mathrm{L}$ torna-se potencialmente tóxica para a vida aquática. ${ }^{3}$

Há também uma preocupação com a doença de Alzheimer causada pelo uso excessivo de sais de alumínio, ${ }^{4}$ servindo, com efeito, de forte interesse para a sociedade. Tais efeitos negativos dos compostos químicos à saúde pública e vida aquática têm motivado pesquisadores a explorarem tecnologias de tratamento de água mais verdes e sustentáveis, como a biocoagulação, eletrocoagulação, célula decombustível microbiana, tecnologia de membranas, etc. ${ }^{5,6}$

Em tais tecnologias, os coagulantes naturais estão atraindo a atenção dos pesquisadores há muito tempo, sendo a razão de sua abundância, biodegradabilidade e inocuidade. Vários estudos sobre coagulantes naturais, extraídos de microrganismos, animais e plantas, são realizados, ${ }^{7,8}$ a fim de mitigar/anular os efeitos tóxicos de efluentes contaminados em água.

Assim, o objetivo desta revisão é apresentar os diferentes tipos de coagulantes naturais, seus respectivos usos e características a fim de informar pesquisadores do setor acerca da possibilidade de utilização para tal ou qual processo de tratamento deágua, seja para o uso dealgum coagulante natural específico individualmente, seja ele associado com demais tecnologias de tratamento, servindo apenas para promover um aprimoramento de outro processo de degradação química.

\section{MATERIAL E MÉTODOS}

Utilizaram-se diversos artigos que se relacionam com a questão dos coagulantes naturais 
por meio dos principais sites de busca de artigos científicos: SciFinder, PubMed, Capes, Scielo, ScienceDirect, Springer e Plos, os quais possuem maior relevância também na área de Biotecnologia Ambiental. Cerca de 160 artigos foram pesquisados, sendo 38 efetivamente utilizados. $\mathrm{O}$ uso de palavras-chave como coagulantes naturais, moringa, quiabo, quitosana e outros coagulantes ocorreram em larga escala, sempre no idioma Inglês, com sua respectiva tradução para o Português, o que aumenta a amplitude, relevância e profundidade da pesquisa.

\section{O TRATAMENTO DA ÁGUA SOB A PERSPECTIVA HISTÓRICA}

Se a necessidade do consumo de água é inerente a qualquer ser humano, logo antes de qualquer atividade rudimentar antiga, como fazer fogo ou construir tendas, o homem já se encontrava em uma situação em que o consumo de água potável era necessário. Desse modo, como é possível imaginar, evidências de quase todos os períodos históricos sugerem que as pessoas tomaram medidas para garantir uma bebida fresca e salutar. ${ }^{9}$

No entanto, a qualidade era melhor ou pior de acordo com os padrões rudimentares e antigos adotados de tratamento, e, de qualquer modo, somente hoje se adotaram critérios físicoquímicos de análise nos quais se sabe que não significa que apenas por a água ser agradável ao paladar que é necessariamente segura para se beber. Os primeiros humanos pensavam que era somente no aspecto físico, uma vez que era o que enxergavam e sentiam sob o aspecto de cor e odor, considerando que o gosto e a aparência da água determinavam sua pureza sem saber que pudesse conter organismos causadores de doenças. ${ }^{9}$
Ainda assim, os esforços desses pioneiros no tratamento de água não foram em vão. Foi por meio de suas tentativas e erros que agora se sabe como tornar a água segura para beber. Há 4.0oo anos, na Índia e em partes da China, os hindus criaram os primeiros padrões registrados de água potável, os quais direcionavam seu povo para aquecer a água suja ao ferver e expor à luz do sol, mergulhando sete vezes em um pedaço de cobre quente, depois filtrá-la e resfriá-la em um recipiente de barro. Esse tratamento esclarecido não apenas produziu água esteticamente aceitável, mas uma fonte potável desinfetada. Tal tratamento era destinado a indivíduos e famílias, não a um abastecimento público de água. ${ }^{9}$

Após os anos de 1.500 a.C., os egípcios descobriram o princípio da coagulação. Eles aplicaram o alúmen químico para o assentamento de partículas suspensas. Há registros dessa técnica de purificação que foram encontrados na parede do túmulo de Amenophis II e Ramsés II em Tebas, esculpidos por volta do ano de 1450 a.C. ${ }^{9}$

Em decorrência dos avanços da ciência e da tecnologia, que ocorreram em especial após a Idade Média, houve uma maior percepção de que a água de aparência limpa não era necessariamente água potável. Antes da invenção do microscópio, a ideia da vida microscópica era inimaginável. Mesmo com essa ferramenta, demorou mais de 200 anos até que uma conexão entre micróbios e doenças fosse feita. ${ }^{9}$

Nos Estados Unidos, os sistemas municipais de abastecimento de água tiveram origem em 1799 . Em 1860, mais de 400 desses sistemas estavam em serviço fornecendo água para as principais cidades e vilas. Em razão da falta de padrões de qualidade da água, esses sistemas contribuíram 
para os principais surtos de doenças por meio da disseminação de organismos patogênicos. ${ }^{9}$

Os coagulantes metálicos, como os sais férricos, possuem tratamento da água desde 1880 . Na década de 1890 , técnicas eficazes de tratamento de água começaram a se desenvolver. Como o desempenho desses coagulantes químicos usuais é duvidoso em certas condições de trabalho, como em baixas temperaturas, os desenvolvimentos em curso resultaram na introdução de polimerização de coagulantes de alumínio. ${ }^{10}$

Assim, a disseminação global do alumínio como coagulante para o abastecimento público de água ocorreu no século XIX e, desde então, a China tornou-se o primeiro consumidor de alumínio do mundo para a clarificação da água, sendo um modelo, nesse sentido, aos demais países do globo. ${ }^{10}$

Em meados doséculoXIXficou provadoquea cólera se espalhava por águas contaminadas. No final do século XIX, Louis Pasteur desenvolveu a teoria dos micróbios particulados da doença, o que finalmente permitiu estabelecer uma relação de causa e efeito entre micróbios e doenças. A filtragem da água foi estabelecida como um método de clarificação dela no século XVIII. Em 1832, a primeira estação municipal de tratamento de água foi construída na Escócia. Infelizmente, as propriedades estéticas da água eram as principais preocupações da época, enquanto seus padrões de qualidade permaneciam ausentes até o final do século XIX. ${ }^{9}$

Acoagulaçãoea floculaçãopodemserobtidas utilizando-se coagulantes naturais ou coagulantes químicos. Os coagulantes naturais, entre os dois, têm sido mais reconhecidos por sua aplicação na purificação tradicional de água. ${ }^{10}$ Coagulação e filtração rápida de areia foram instituídas, o que reduziu significativamente a turbidez e as bactérias no abastecimento de água. A cloração da água foi finalmente introduzida em 1908 e, com isso, o abastecimento de água de uma comunidade poderia, de fato, ser considerado seguro. ${ }^{9}$

\section{COAGULANTES COMO CONDICIONADORES}

Para melhorar as tecnologias atuais do tratamento de água, os coagulantes naturais são adicionados durante a separação sólido-líquida do lodo, que envolve a coagulação/floculação, decantação e desidratação, ${ }^{11}$ tanto condicionadores químicos quanto naturais, os quais melhoram a separação sólido-líquida do lodo por meio de mecanismos como a neutralização de carga e/ ou pela ponte de partículas. ${ }^{12}$ A adição desses condicionadores na água contaminada visa reduzir a afinidade do lodo com a água, alterando a forma de lodo existente na água, com o objetivo de obter uma fácil desidratação. ${ }^{13}$

Eles são considerados primeiramente como coagulantes e depois qualificados como floculantes. ${ }^{14}$ No entanto, na maioria dos casos, os condicionadores desempenham o duplo papel de fornecer neutralização de carga e ponte de partículas. No caso de tratamento de lodo, os condicionadores desestabilizam partículas carregadas negativa ou positivamente, aumentando, assim, a agregação e a formação de flocos. Eles interagem com as partículas carregadas negativamente de lama, que é composta de água, células e substâncias poliméricas extracelulares (EPS). As EPS mostraram ter um papel importante na compreensão do mecanismo real subjacente ao tratamento de lodo, particularmente em processos de lodo condicionado. ${ }^{15}$ 


\section{A RELEVÂNCIA DOS POLIELETRÓLITOS COMO COAGULANTES}

Fazendo-se importante a análise separada do termo coagulação, edepois contextualizá-la com aquestão natural, diferenciando-a da química, temse que é originário do latim coagulare, significando "manter-se junto". ${ }^{16}$ Trata-se de um processo que descreve o efeito produzido pela adição de um produto químico sobre uma dispersão coloidal, o que resulta na desestabilização das partículas por meio da redução das forças, que tendem a mantêlas separadas. Em outras palavras, a coagulação pode ser entendida como a desestabilização da dispersão coloidal, alcançada mediante forças de atração entre partículas por meio da adição de produtos coagulantes apropriados, seguidos por agitação para homogeneização da mistura. ${ }^{16,17}$

A coagulação é conhecida como o condicionamento químico de coloides, envolvendo a adição de produtos químicos que visam modificar as propriedades desses coloides, de modo a aumentar a eficiência de remoção. Com efeito, a escolha do coagulante e sua aplicabilidade são fatores importantes para o tratamento de água e efluentes industriais. ${ }^{16}$

Os coagulantes mais empregados são os inorgânicos (sais de alumínio e ferro), havendo também a utilização dos coagulantes orgânicos com densidade de carga positiva chamados de polímeros catiônicos, podendo ser sintéticos ou naturais. Sua diferença está na reação hidrolítica com a água, sendo que nos polieletrólitos as cadeias polimerizadas são formadas quando adicionados ao meio líquido. ${ }^{16}$

Os produtos adicionados para o tratamento de água e efluentes são conhecidos como condicionadores, podendo ser polieletrólitos sintéticos (poliacrilamida (PAM), polietilenoimina
(PEI)), naturais (como quitosana, Moringa oleifera (MO), Jatropha Curcas, Prosopis juliflora, goma guar, Calotropis procera, Cactus latifaria e Clidemia angustifolia) e inorgânicos (cal, alume, cloreto de polialumínio (PAC) e cloreto férrico). ${ }^{16}$

Polieletrólitos (PE), um tipo de coagulante, consiste em polímeros com grupos ionizáveis ao longo da cadeia, classificados em aniônicos e catiônicos de acordo com seu grupo funcional, podendo ser não iônico também. Polieletrólitos são constituídos de complexos de grandes cadeias moleculares, que exibem sítios com cargas positivas ou negativas, com capacidade de adsorção de partículas ao seu redor. ${ }^{18}$

Em razão disso, é que quando a coagulação/ floculação é realizada por eletrólitos, não existem reações de neutralização entre o coagulante e a água para formar complexos gelatinosos, como ocorre com os coagulantes derivados de sais de alumínio e ferro. Portanto, a coagulação/floculação por eletrólitos praticamente independe da alcalinidade da água, podendo também ocorrer em uma grande faixa de valores de $\mathrm{pH}$ entre 4,0 e 12,0. ${ }^{16}$

No que se refere aos coagulantes metálicos, outro tipo de coagulante, têm sido os mais utilizados para o tratamento de água bruta. Eles possuem a capacidade de agir como coagulantes e floculantes e, quando são dissolvidos, formam compostos complexos hidratados. Sendo sulfato de alumínio, sulfato férrico, sulfato ferroso, cloreto férrico e aluminato de sódio os mais utilizados. ${ }^{18}$

Portanto, a despeito da importância relativa de coagulantes polieletrólitos, como também os coagulantes metálicos, o foco será os coagulantes orgânicos, tanto de carga positiva quanto negativa, porém especificamente naturais. Isso ocorre especialmente pelo fato de que a utilização de 
coagulantes naturais não requer ajustes de $\mathrm{pH}$ e alcalinidade, não causam problemas de corrosão, além de ser uma alternativa barata, viável e ambientalmente mais adequada. Há também a geração de pouco lodo, e este é biodegradável. ${ }^{16}$

Conceitualmente, espera-se que a coagulação elimine partículas e coloides por meio de um coagulante, como alúmen ou cloreto férrico, enquanto a desinfecção é aplicada para inativar agentes patogênicos por desinfetantes como cloro aquoso. Assim, há pesquisadores que se preocupam com a qualidade da matéria orgânica natural (NOM) e a presença de algas nas águas superficiais, bem como com as dificuldades encontradas na remoção no tratamento da água. ${ }^{19}$ De acordo com eles, o tratamento de pré-cloração para a água bruta provou aumentar a concentração de carbono orgânico dissolvido em razão da lise de células de algas e da formação de subprodutos de desinfecção. Para eles, nenhuma pré, tampouco inter-, apenas pós-cloração precedida por coagulação otimizada para NOM, sendo a remoção de algas a melhor tecnologia disponível para o tratamento de água convencional que seria reforçada pelo menos pela adsorção em carvão ativado em pó ou nanofiltração.

SegundoGhernaout, Moulay, Messaoudene, Aichouni, Naceur e Boucherit, 19 um nível baixo de Trihalometanos (THM) pode ser obtido pela otimizaçãodecadapassodetratamento. Coagulantes como $\mathrm{Fe}_{3}{ }^{+}$e tratamentos de filtração lenta removem concentrações significativas de precursores de TOC (Carbono orgânico total) e THM, especialmente a porção de HPO (hidrofóbica). Para os autores, a pré-cloração deve ser abandonada em decorrência da lise de células de algas; o crescimento de algas pode ser controlado com limpeza mais frequente dos locais armazenadores.

\section{OS COAGULANTES NATURAIS}

Pode-se dizer que os coagulantes naturais atuam em sistemas de partículas coloidais, neutralizando cargas e formando pontes entre essas partículas, sendo esse processo responsável pela formação de flocos. ${ }^{20}$

Oscoagulantes naturaissãoprincipalmente polissacarídeos ou proteínas, cuja funcionalidade é semelhante à dos coagulantes químicos, porém, tratam de sua vantagem por serem biodegradáveis e não apresentarem toxicidade, além de formarem, como já dito, lodos em quantidades reduzidas se comparadas com as dos coagulantes químicos, e com menores teores de metais. ${ }^{20}$ Tais lodos são facilmente biodegradáveis e menos volumosos, chegando a apenas 20 a $30 \%$ do que é gerado pelos coagulantes metálicos, como os sais de alumínio, cuja vantagem ainda é não induzir, como pode predispor este último, à doença de Alzheimer. ${ }^{21}$

Em razão disso, os coagulantes naturais, umaespéciedepolímeros, sãomaisfrequentemente usados em conjunto com coagulantes químicos, pois exibiram eficiências de remoção de turbidez restritas quando usados isoladamente, ${ }^{10}$ sendo eles capazes de tratar a água de águas turvas com alto grau de eficiência, chegando a cerca de 98\%, tornando a água potável nesse parâmetro, isto é, de turbidez. ${ }^{21}$ Um valor crítico de cinco unidades de turbidez nefelométrica (NTU) para a turvação residual na água potável após o tratamento foi estabelecido pela Organização Mundial de Saúde (OMS), sendo que um valor máximo permitido para água tratada é de 1 NTU. ${ }^{22}$

Os coagulantes naturais mais comumente utilizados, de acordo com mais de 50\% da bibliografia levantada, são o Tanfloc SG, a Moringa oleífera, além de estudos quanto à funcionalidade 
do Abelmoschus esculentus, ou como comumente conhecido, quiabo. É possível incluir também as sementes de nirmali; entre o tanino e o cáctus, ${ }^{23,24,25}$ somente o tanino não é baseado em planta. ${ }^{24}$

A possibilidade de usar coagulantes à base de plantas no tratamento de efluentes é bastante útil em termos de alcançar objetivos ambientais, de saneamento e desenvolvimento sustentável, pois esses coagulantes são geralmente considerados seguros para a saúde humana, com baixa produção de iodo, baratos e disponíveis localmente, portanto, globalmente acessíveis. ${ }^{25}$

A Tabela 1 abaixo apresenta os diferentes tipos de coagulantes com suas respectivas características físico-químicas, de acordo com as respectivas referências.

\section{TIPOS DE COAGULANTES NATURAIS}

\subsection{PRINCIPAIS COAGULANTES NATURAIS NÃO BASEADOS EM PLANTA}

Entre os tipos de coagulantes naturais não baseados em plantas, o Tanfloc, o tanino e a Quitosana são os que apresentam maior relevância. Com relação ao tanino, é um nome geral atribuído a grandes compostos de polifenol obtidos de materiais naturais, como o extrato orgânico de casca de árvore e madeira. Experimentos em laboratório demonstraram que é possível sintetizar coagulante derivado de tanino a partir de diversos estoques de taninos por meio de um procedimento muito simples que envolve a reação de base de Mannich. No entanto, a complexidade química dos taninos e o fato de serem geralmente retirados

Tabela 1 - Tipos de coagulantes e suas características físico-químicas.

\begin{tabular}{|c|c|c|c|c|c|}
\hline & $\begin{array}{c}\text { Tipo de } \\
\text { Coagulante } \\
\text { Natural }\end{array}$ & Fonte & $\begin{array}{l}\text { Características de } \\
\text { condicionamento }\end{array}$ & Agente Ativo (AA) & Principais mecanismos \\
\hline $1^{26,27,28,29}$ & Moringa Oleifera & Planta & Coagulante & $\begin{array}{l}\text { Polímero orgânico; } \\
\text { Peptídeos catiônicos }\end{array}$ & $\begin{array}{l}\text { Adsorção. Neutralização de carga } \\
\text { de absorção. }\end{array}$ \\
\hline $2^{20,24,30}$ & Tanino & $\begin{array}{l}\text { Não baseado } \\
\text { em planta }\end{array}$ & $\begin{array}{l}\text { Coagulante e } \\
\text { floculante }\end{array}$ & $\begin{array}{l}\text { Polieletrólito } \\
\text { catiônico }\end{array}$ & $\begin{array}{l}\text { Cobertura de neutralização de } \\
\text { carga, adsorção, precipitação } \\
\text { eletrostática. }\end{array}$ \\
\hline $3^{31}$ & Tanfloc & $\begin{array}{l}\text { Não baseado } \\
\text { em planta }\end{array}$ & $\begin{array}{l}\text { Coagulante e } \\
\text { floculante }\end{array}$ & $\begin{array}{l}\text { Polieletrólito } \\
\text { catiônico }\end{array}$ & $\begin{array}{l}\text { Auxiliar de coagulação, renovável. } \\
\text { Coagulante/Floculante catiônico } \\
\text { de baixo peso molecular, insumo } \\
\text { essencialmente vegetal. }\end{array}$ \\
\hline $4^{25,32}$ & Cáctus & Planta & $\begin{array}{l}\text { Coagulante e } \\
\text { floculante }\end{array}$ & & $\begin{array}{l}\text { Biocoagulante e floculante, } \\
\text { biossorção, auxiliar na remoção } \\
\text { de turbidez. Coagulação e } \\
\text { neutralização. }\end{array}$ \\
\hline $5^{33,34}$ & $\begin{array}{l}\text { Sementes de } \\
\text { Nirmali }\end{array}$ & Planta & Coagulante & $\begin{array}{l}\text { Polieletrólitos } \\
\text { aniônicos }\end{array}$ & $\begin{array}{l}\text { Biocoagulante, não generativo e } \\
\text { neutralizante. }\end{array}$ \\
\hline $635,36,37$ & $\begin{array}{l}\text { Quiabo } \\
\text { (Abelmoschus } \\
\text { esculentu) }\end{array}$ & Planta & $\begin{array}{l}\text { Coagulante e } \\
\text { floculante }\end{array}$ & Polímero aniônico & $\begin{array}{l}\text { Auxiliar de Floculação e Filtração, } \\
\text { bem como varredura, adsorção e } \\
\text { neutralização. }\end{array}$ \\
\hline $7^{5,13,16}$ & Quitosana & $\begin{array}{l}\text { Não baseado } \\
\text { em planta }\end{array}$ & Coagulante & $\begin{array}{l}\text { Polímero } \\
\text { pseudocatiônico }\end{array}$ & $\begin{array}{l}\text { Bioadesivo, biocompatível e } \\
\text { biodegradável. }\end{array}$ \\
\hline
\end{tabular}


de uma matriz natural sem uma purificação muito completa, tornam o conhecimento de sua estrutura uma tarefa difícil de ser realizada. ${ }^{20,24,30,31}$

Tanfloc é o nome de um novo coagulante à base de tanino com origem natural. Apresenta uma alta atividade coagulante, pois uma dose relativamente baixa (200 $\mathrm{mg} / \mathrm{L}-1)$ pode remover quase toda a concentração inicial de algum contaminante. ${ }^{31}$ A Quitosana, por sua vez, é não tóxica, biodegradável, não corrosiva e segura de manusear. Os efluentes gerados por ela podem ser descartados com um impacto ambiental menor do que aqueles que usam o metal comum e o polímero sintético. ${ }^{17}$

\subsection{PRINCIPAIS COAGULANTES NATURAIS BASEADOS EM PLANTAS}

Alguns pesquisadores revisaram o uso de coagulantes à base de plantas no tratamento deágua e esgoto. ${ }^{23}$ Entre os fatores que contribuem para o interesse no uso de coagulantes à base de plantas, trata-se especialmente da presença de monômeros residuais durante o uso de polímeros sintéticos, que são indesejáveis em razão da sua neurotoxicidade e propriedades carcinogênicas. Os coagulantes à base de plantas são projetados com tecnologias de ponta e já possuem certo custo-benefício se comparados às suas contrapartes químicas. Os biocoagulantes atingem uma eficiência de tratamento comparável aos coagulantes químicos quando empregados no tratamento de águas com faixa de turbidez baixa com média de 50 a 500 NTU. ${ }^{25}$

É possível verificar, por meio de diversos estudos, que a Moringa oleífera, além de uma série de benefícios trazidos à saúde humana, e também por ser comestível, é não tóxica, bem como capaz de eliminar a turvação e as matérias orgânicas dissolvidas da água de rio; também elimina a alcalinidade, sólidos totais dissolvidos e dureza.
Ainda, entre outras funções, apresenta capacidade de remoção de metais tóxicos de corpos de água e de biofilmes bacterianos. ${ }^{26,27,28,29}$

A população da planta nirmali está se esgotando rapidamente em decorrência do mecanismo não autodegenerativo nos frutos. Eles são frequentemente deteriorados e propensos a ataques fúngicos assim que caem. A semente da árvore nirmali Strychnos potatorum Linn, além de ser utilizada no tratamento de diversas doenças como gonorreia, doenças oculares, bronquite e ter diversos efeitos anti-inflamatórios, mostra propriedades de coagulação no clareamento de água turva. Essa propriedade foi atribuída à presença de polieletrólitos aniônicos com grupos de superfície - $\mathrm{OHOH}$ e $\mathrm{OH}$ livres que estão presentes na proteína da semente.33,34

Ainda dentro da abordagem dos coagulantes naturais à base de plantas, há pesquisas que se voltam para a investigação do uso de espécies de cactos, com múltiplos estudos buscando estabelecer a eficácia da planta como coagulante. Sendo as seguintes espécies as mais conhecidas e estudadas como coagulantes naturais: Opuntia ficus-indica, Opuntia dillenii e Opuntia stricta. ${ }^{25}$

O cáctus é uma planta nativa de vários países, especialmente os extremamente quentes e áridos, visto que se trata de uma planta adaptada a ambientas como estes. Seu uso como coagulante requer, primeiramente, uma visão geral de seus níveis de eficácia e condições ótimas de utilização, especialmente com relação ao $\mathrm{pH}^{25}$

Alguns pesquisadores avaliaram o desempenho do cáctus Opuntia fícus-indica como agente floculante. ${ }^{22}$ Coletando cacto em Tipaza, Algeria, pesquisadores avaliaram o desempenho de coagulação/floculação do cacto e a qualidade 
da água tratada por meio da medição da turbidez residual. Embora a eficiência da remoção da turbidez seja maior quando a moringa é aplicada como agente, ainda assim depois de medir a eficácia do cacto na coagulação em diferentes soluções, os resultados demonstraram que a concentração de palma $0,2 \mathrm{mg} / \mathrm{L}$ foi eficaz para a água mais turva, alcançando uma remoção de o,5 NTU. Os níveis residuais de turbidez estavam entre $0,5 \mathrm{e}$ 1,2 NTU, com os resultados sendo dependentes da turbidez inicial da água. Esses achados levaram os pesquisadores a concluírem que a mucilagem de O. ficus-indica é eficiente como agente tecnológico natural para o tratamento de água. ${ }^{25}$

Uma pesquisa realizada por Beyene, Hailegebrial e Dirersa ${ }^{1}$ tratou da efetividade de cacto em pó, alúmen e sua combinação de análises físico-químicas de amostra de água, como $\mathrm{pH}$, condutividade, salinidade e turbidez usando o Jar-Test (ou Teste de Jarros) para determinação de dosagens ótimas de coagulantes. O resultado dessa pesquisa indicou uma remoção anterior de turbidez, sem a aplicação da técnica, de $23,9 \%$ para 54\%, quando a técnica foi adotada. Ademais, passou-se de 28,46\% para $58,2 \%$ à medida quea doseaumentou de o, 50 para 3,50 g tanto para o pó de cacto quanto para alúmen, respectivamente. $\mathrm{O}$ resultado também revelou que o pó de cacto é mais eficiente em manutenção de $\mathrm{pH}$, manutenção de Sólidos Totais Dissolvidos (TDS) e remoção de salinidade do que o alúmen, mas sua combinação é a mais eficiente em termos de remoção de turvação, redução de salinidade, redução de condutividade e redução de TDS, tendo um efeito marginal sobre o valor de oxigênio dissolvido (DO).

Tal estudo também mostrou a porcentagem de remoção de oxigênio dissolvido total (TDO) da água bruta. ${ }^{1}$ Desse modo, possuindo o pó de cacto forte potencial de consistência na remoção de turvação, implica o fato de que o cacto pode servir como coagulante no tratamento da água. $\mathrm{O}$ coagulante natural não teve efeito significativo sobre o $\mathrm{pH}$ em comparação com coagulantes químicos, e em geral não tem mesmo. ${ }^{25}$ Por fim, a combinação de pó de alúmen e cacto demonstrou-se um bom coagulante natural para remoção de turbidez, remoção de salinidade, manutenção de $\mathrm{pH}$ e condutividade e outros parâmetros físico-químicos da água. ${ }^{1}$

Ainda, o cáctus, além de ser considerado um coagulante que possui apelo ambiental por ser sustentável especialmente em decorreência de sua atividade florística em vez de sintética, é também um forte aliado da preocupação ambiental por servir de auxiliar na biorremediação de áreas contaminadas, especialmente no uso da espécie Opuntia ficus-indica (OFI). ${ }^{38}$

\section{CONSIDERAÇÕES FINAIS}

Nesta revisão buscou-se apresentar os diferentes tipos de coagulantes naturais para o tratamento de água e efluentes a fim de promover um pensamento sustentável e ambientalmente mais adequado, em que as abordagens estiveram voltadas para a eficácia deles frente aos mais convencionais, que são os coagulantes químicos. Verificou-se que as questões que envolvem a pesquisa dos coagulantes naturais é um caminho ambientalmente correto, barato e um objetivo a ser alcançado, visto a grande demanda de tratamento de água e efluentes que ocorre ao redor do mundo. Desse modo, são necessários mais estudos que se voltem para os coagulantes naturais baseados e não baseados em plantas, bem como para novos coagulantes - haja vista a grande quantidade de biodiversidade desconhecida - que podem também possuir potencial de coagular/flocular diversos tipos de substâncias. 


\section{REFERÊNCIAS}

1. Beyene HD, Hailegebrial, TD, Dirersa, WB. Investigation of Coagulation Activity of Cactus Powder in Water Treatment. J. appl. chem. 2016 Nov 30;9.

2. Muyibi SA, Noor MJMM, Ong DT, Kai KW. Moringa oleifera seeds as a flocculant in waste sludge treatment. Int. j. environ. stud. 2001;58(2):185-195.

3. Deppe T, Benndor J. Phosphorus reduction in a shallow hypereutrophic reservoir by in-lake dosage of ferrous iron. Water Res. 2002;36(18):4525-34.

4. Martyna CN, Osmonda C, Edwardson JA, Barkera DJP, Harris EC, Lacey RF. Geographical relation between alzheimer's disease and aluminium in drinking water. The Lancet. 1989;8629(333):61-62.

5. Li WW, Yu H-Q, He Z. Towards sustainable wastewater treatment by using microbial fuel cells-centered Technologies. Energy Environ. Sci. 2013;7:911-24.

6. Razali M, Kim JF, Attfield M, Budd PM, Drioli E, Lee YM, et al. Sustainable wastewater treatment and recycling in membrane manufacturing. Green Chem. [Internet]. 2015 [cited $2018 \mathrm{Apr}$ 26];17:5196-205. Available from: http://pubs.rsc.org/en/content/articlehtml/2015/gc/c5gco1937k

7. Ganjidoust H, Tatsumi K, Yamagishi T, Gholian, R. Effect of synthetic and natural coagulant on lignin removal from pulp and paper wastewater. Water Sci. Technol. [Internet]. 1997 [cited 2018 Apr 26];35:291-6. Available from: http://linkinghub.elsevier.com/retrieve/pii/So273122396009432

8. Jeon JR, Kim EJ, Kim YM, Murugesan K, Kim JH, Chang YS. Use of grape seed and its natural polyphenol extracts as a natural organic coagulant for removal of cationic dyes. Chemosphere. 2009;77(8):1090-98.

9. Dwarapureddi BK, Saritha V. Plant based coagulants for point of use water treatment - a review. Current environ. Eng. 2016;61-76.

10. Choy SY, Prasad KMN, Wu TY, Raghunandan ME, Ramanan RN. Utilization of plant-based natu1o. ral coagulants as future alternatives towards sustainable water clarification. J. environ. sci. 2014;26(11):2178-89.

11. Guibal E, Roussy J. Coagulation and flocculation of dyecontaining solutions using a biopolymer (chitosan). React. Funct. Polym. 2007;67(1):33-42.

12. Chen L, Chen D, Wu C. Insight into flocculation mechanism of chitosan. J Donghua Univ (Eng. Ed.). 2003;20(1):90-93. 
13. Liu B, Song H, Li Y. Effect of chitosan/polymeric aluminum composite flocculant on activated sludge. Adv Mat Res. 2011;383-90.

14. Yang R, Li H, Huang M, Yang H, Li A. A review on chitosan-based flocculants and their applications in water treatment. Water Res. 2016;95:59-89.

15. Baumann ER. Water quality and treatment: a handbook of public water supplies. AlChE J. 1971;18(2).

16. Faye MCAS, Zhang Y, Yang J. Extracellular polymeric substances and sludge solid/liquid separation under Moringa oleifera and chitosan conditioning: a review. Environ. Tech. Rev. 2017;1(6):59-73.

17. Qasim SR, Motley EM, Zhu G. Water Works Engineering - Planning, Design \& Operation. Prentice Hall PTR. 2000;844.

18. Guzmán LV, Ángel TC, García R. (2013). Reducción de la turbidez del agua usando coagulantes naturales: una revisión. Revista U.D.C.A Actua. Divulg. Cien. [Internet]. 2013 Jan-June 2013 [cited 2018 June 29];16(1):253-62. Available from: http://www.scielo.org.co/scielo.php?script=sci_arttext\&pid=So123-42262013000100029\&lng=en\&tlng=es

19. Ghernaout D, Moulay S, Messaoudene NA, Aichouni M, Naceur MW, Boucherit, A. Coagulation and chlorination of NOM and algae in water treatment. A review. J. environ. monit. [Internet]. 2014 [cited 2018 June 29];6(2):23-34. Available from: http://www.sciencepublishinggroup.com/j/ ijema

20. Graham N, Gang F, Geoffrey F, Watts M. Characterisation and coagulation performance of a tannin-based cationic polymer: A preliminary assessment. Colloids Surf. A Physicochem. Eng. Asp. 2008 Sept;327(1-3):9-16.

21. Saranya P, Ramesh ST, Gandhimathi R. Effectiveness of natural coagulants from non-plant-based sources for water and wastewater treatment. Desalination and Water Treatment. 2013;52:603039.

22. Nefale AD, Kamika I, Obi CL, Momba MNB. The Limpopo Non-Metropolitan Drinking Water Supplier Response to a Diagnostic Tool for Technical Compliance. Int J Environ Res Public Health. 2017;14(7):810.

23. Vijayaraghavan G, Sivakumar T, Kumar VA. Application of plant based coagulants for waste water treatment. Int J Adv. Eng Res Stud. [Internet]. 2011 [cited 2018 Mar 15];88-92. Available from: https://pdfs.semanticscholar.org/f5dc/1a3896cdific67eoc277ebfbe970e8afae89.pdf 
24. Aboulhassan MA, Souabi S, Yaacoubi A, Baudu M. Coagulation efficacy of a tannin coagulant agent compared to metal salts for paint manufacturing wastewater treatment. Desal. wat. treat. [Internet]. 2016 [cited $2018 \mathrm{Apr} 18$ ];57(41). Available from: https://www.tandfonline.com/doi/ abs/10.1080/19443994.2015.1101016?journalcode=tdwt20.

25. Karanja A, Fengting L, Ng'ang'a W. Use of cactus opuntia as a natural coagulant: water treatment in developing countries. Int. J. Adv. Res. 2017;5(3):884-94.

26. Formentini-Schmitt DM, Fagundes-Klen MR, Veit MT, Palácio SM, Trigueros DEG, Bergamasco R, et al. Potential of the Moringa oleifera saline extract for the treatment of dairy wastewater: application of the response surface methodology. Environ Technol. 2018;40(17):2290-99.

27. Galan CR, Silva MF, Mantovani D, Bergamasco R, Vieira MF. Green synthesis of copper oxide nanoparticles impregnated on activated carbon using Moringa oleifera leaves extract for the removal of nitrates from water. Wiley Onle Library. 2018;96(11):2378-86.

28. Tavares FO, Pinto LAM, Bassetti FJ, Vieira MF, Bergamasco R, Vieira AMS. Environmentally friendly biosorbents (husks, pods and seeds) from Moringa oleifera for $\mathrm{Pb}$ (II) removal from contaminated water. Environ Technol. 2017;38(24):3145-55.

29. Oliveira AM, Férnandes MS, Abreu Filho BA, Gomes RG, Bergamasco R. Inhibition and removal of staphylococcal biofilms using Moringa oleifera Lam. aqueous and saline extracts. J Env. Chem. Eng. 2018;6(2):2011-16.

30. Barrado-Moreno MM, Beltrán-Heredia J, Martín-Gallardo J. Removal of Oocystis algae from freshwater by means of tannin-based coagulant. J Appl Phycol. 2016;28:1589-95.

31. Beltrán-Heredia J, Sanchez-Martin J, Martin-Sanchez C. Remediation of dye-polluted solutions by a new tannin-based coagulant. Ind. Eng. Chem. Res. 2011;50(2):686-93.

32. Fedala N, Lounici H, Drouiche N, Mameri N, Drouiche M. Physical parameters affecting coagulation of turbid water with Opuntia ficus-indica cactus. Ecol. Eng. 2015;77:33-36.

33. Yadav KN, Kadam PV, Patel JA, Patil MJ. Strychnos potatorum: revisão fitoquímica e farmacológica. Pharmacogn Rev. 2014;15(8):61-66.

34. Sarawgi G, Kamra A, Suri N, Kaur A, Sarethy IP. Effect of Strychnos potatorum Linn. Seed Extracts on Water Samples from Different Sources and with Diverse Properties. Water Environ. Pollut. 2009;6(3):13-17.

35. Okolo BI, Nnaji PC, Menkiti MC, Onukwuli OD. A kinetic investigation of the pulverized okra pod induced coag-flocculation in treatment of paint wastewater. American J Anal. Chem. 2015;7(6):610-22. 
36. Freitas TKFS, Oliveira VM, Souza MTF, Geraldino HCL, Almeida VC, Fávaro SL, et al. Optimization of coagulation-flocculation process for treatment of industrial textile wastewater using okra (a. esculentus) mucilage as natural coagulant. Ind. Crops Prod. 2015;76:538-44.

37. Fahmi MR, Hamidin N, Abidin CZA, Fazara MAU, Hatim MDI. Performance evaluation of okra (abelmoschus esculentus) as coagulant for turbidity removal in water treatment. Muham. Ridw. Fahmi. 2014;594-95, 226-30.

38. Nharingo T, Moyo M. Application of Opuntia ficus-indica in bioremediation of wastewaters. A critical review. J. environ. manag. 2015;166:55-72. 
